\title{
Protective Cardiorenal Effects Of Tropaeolum majus L. In Rats With Renovascular Hypertension
}

\author{
Arquimedes Gasparotto Junior ${ }^{1 *}$, Thiago Bruno Lima Prando², Karimi Sater Gebara, Francielly Mourão Gasparotto', Francislaine Apareci- \\ da dos Reis Lívero', Dênis Pires de Lima ${ }^{3}$, Roberto da Silva Gomes ${ }^{4}$ and Emerson Luiz Botelho Lourenço ${ }^{2}$ \\ 'Laboratory of Electrophysiology and Cardiovascular Pharmacology, Federal University of Grande Dourados, Dourados, MS, BRAZIL. \\ 2Laboratory of Pharmacology of Natural Products, Paranaense University, PR, BRAZIL. \\ ${ }^{3}$ Synthesis and Transformation of Organic Molecules Laboratory, Federal University of Mato Grosso do Sul, Campo Grande, MS, BRAZIL. \\ ${ }^{4}$ Faculty of Exact Sciences and Technology, Federal University of Grande Dourados, Dourados, MS, BRAZIL.
}

\begin{abstract}
Background: Tropaeolum majus L. (Tropaeolaceae) is an important medicinal plant belonging to the Tropaeolaceae family, which has 80 species distributed in South and Central America. In Brazil, it is distributed practically throughout the entire territory and it is popularly known as "capuchinha". In folk medicine its leaves are widely used for treatment of cardiovascular disorders. Despite consistent data showing some acute effects on renal and cardiovascular system, no study has investigated whether Tropaeolum majus extracts is able to exert cardiorenal protective effects after 30 days of treatment, i.e. in a sustained manner. Objective: Investigate the prolonged cardiorenal protective effects of ethanolic extract obtained from Tropaeolum majus (EETM) in rats with renovascular hypertension. Material and Methods: First, EETM was obtained and chemically characterized. Then, we investigated the possible antihypertensive and diuretics effects, including effects on renal haemodynamics, after prolonged treatment ( 30 days) with EETM $(3,30$ and $300 \mathrm{mg} / \mathrm{kg}$ ). Finally, we examined whether treatment with EETM may affect the angiotensin-converting enzyme (ACE) and oxidative stress, preventing heart and kidney damage in two-kidney, one-clip (2K1C) Goldblatt hypertensive rats. Results: Prolonged treatment with EETM was able to prevent the evolution of renovascular
\end{abstract}

hypertension in $2 \mathrm{~K} 1 \mathrm{C}$ rats, inducing important renoprotective effects and reducing systemic blood pressure and cardiac hypertrophy. Moreover, it was also identified that these effects may be directly related to significant ACE inhibitory activity and reduction of oxidative stress. Conclusion: This study has brought new scientific evidence of preclinical efficacy of EETM as a cardiorenal protective agent in rats with renovascular hypertension.

Key words: Antihypertensive, Cardioprotective, Diuretic, Renoprotective, Tropaeolum majus $\mathrm{L}$.

\section{Correspondence :}

Arquimedes Gasparotto Junior, Laboratory of Electrophysiology and Cardiovascular Pharmacology, Faculty of Health Sciences, Federal University of Grande Dourados, Rodovia Dourados-Itahum, km 12, P.O. Box 533, 79.804-970 Dourados, MS, BRAZIL.

Phone no.: +55 (67) 3410-2333, Fax: +55 (67) 3410-2321

Email: arquimedesgasparotto@gmail.com (A. Gasparotto Junior).

DOI: 10.5530/jyp.2017.9.49

\section{INTRODUCTION}

Hypertension, a worldwide public health problem, is responsible for millions of deaths per year. ${ }^{1}$ The disorder, characterized by multiple factors that involves complex interactions between the mechanisms of homeostatic control and environmental factors, is an important risk factor for cardiovascular complications. ${ }^{2}$ Since cardiovascular diseases are progressive and chronic disorders, the treatment has to be performed for a prolonged period resulting in tachyphylaxis, toxicity, and elevate financial cost, which culminates in low adhesion of patients. Thus, drugs based on natural products can be a good therapeutic strategy. ${ }^{3}$ However, most of studies evaluated only acute cardioprotector effects of natural products.

One of these plants is Tropaeolum majus L. (Tropaeolaceae), an important medicinal plant belonging to the Tropaeolaceae family, which has 80 species distributed in South and Central America. In Brazil, it is distributed practically throughout the entire territory and it is popularly known as "capuchinha". In folk medicine its leaves are widely used for urinary infections, asthma, constipation, and cardiovascular disorders. ${ }^{4-6}$ Various compounds belonging to different classes of secondary metabolites have been isolated and identified in T. majus preparations. Glucosinolates, ${ }^{7}$ terpenoids, ${ }^{8}$ and flavonoids, mainly isoquercitrin (chemical marker for the quality control), ${ }^{9}$ are the three major groups of secondary metabolites in the plant, which have been considered responsible for the medicinal properties.

The pharmacological properties attributed to this plant in preclinical studies include antithrombin, ${ }^{10}$ antibacterial, ${ }^{11}$ diuretic,,${ }^{12,13}$ and acute antihipertensive activity. ${ }^{9}$ Toxicological parameters of this species were deeply investigated and showed important safety information. No toxic effects were observed after acute treatment or within 28 days of T. majus extract administration. ${ }^{12,14}$ In addition, T. majus extract was unable to produce (anti) estrogenic or (anti) androgenic activities in the shortterm in in vivo screening assays. ${ }^{15}$

Despite consistent data showing some acute effects on renal and cardiovascular system, no study has investigated whether T. majus extract is able to exert cardiorenal protective effects after 30 days of treatment, i.e. in a sustained manner. So, the present study investigated the prolonged cardiorenal protective effects of ethanolic extract obtained from T. majus (EETM) in rats with renovascular hypertension. First, EETM was obtained and chemically characterized. Then, we investigated the possible antihypertensive and diuretics effects, including actions on renal haemodynamics, after prolonged treatment (30 days). Finally, we examined whether treatment with EETM can produce some response on the angiotensin-converting enzyme (ACE) and oxidative stress, preventing tissue damage in two-kidney, one-clip (2K1C) Goldblatt hypertensive rats.

This is an open access article distributed under the terms of the Creative Commons Attribution-NonCommercial-ShareAlike 4.0 License, which allows others to remix, tweak, and build upon the work non-commercially, as long as the author is credited and the new creations are licensed under the identical terms. 


\section{MATERIAL AND METHODS}

\section{Drugs}

Furosemide, isoquercitrin (ISQ), N-hippuryl-L-histidyl-L-leucine hydrate, o-phthalaldehyde, and captopril, were obtained from Sigma-Aldrich (St. Louis, MO, USA). All other drugs and reagents used were purchased from Merck' (Darmstadt, Germany).

\section{Chemical characterization and standardization of the isoquercitrin content \\ Plant material and preparation of EETM}

T. majus leaves were collected on February 2013 from the botanical garden of the Paranaense University (UNIPAR; Umuarama-PR, Brazil; S23 $3^{\circ} 47^{\prime} 55-\mathrm{W} 53^{\circ} 18^{\prime} 48$ ). A voucher specimen is cataloged at the Herbarium of the University under number 2230. The plant material was air-dried and pulverized. The resulting product was macerated with $70 \%$ ethanol for seven days. The solvent was removed using a spray-drying equipment yielding $12.55 \%$.

\section{Sample solution}

Accurately weighed amounts of the EETM were dissolved in methanol/ water (1:1) to prepare a $5.00 \mu \mathrm{g} / \mathrm{mL}$ solution and the ISQ was identified by preparative High-Performance Liquid Chromatography (HPLC) analysis and quantified using the same chromatographic conditions as used for ISQ standard.

\section{Standard solution}

In order to prepare standard solutions, ISQ standard was dissolved in methanol/water $(1: 1, \mathrm{v} / \mathrm{v})$ in nine different concentrations, from 1.00 to $20.00 \mu \mathrm{g} / \mathrm{mL}$. Preparative and quantitative HPLC analyses were conducted using the conditions described. ${ }^{9}$

\section{High-Performance Liquid Chromatography (HPLC) measurements}

HPLC analyzes were performed on a Shimatzu LC-2010C system coupled to a UV detector. For analysis, we used a RP-18 column $(5 \mu \mathrm{M}$, $225 \times 4.6 \mathrm{~mm}$ ) (LiChrospher, Merck KgaA, Darmstadt, Germany) protected by a guard Merck RP-18 column ( $5 \mathrm{uM}, 4.0$ x $3.0 \mathrm{~mm}$ ). Peak areas were calculated by an integrator Shimatzu LASS-VP 7.2.1.

The analyses were carried out in triplicate, at a flow rate of $0.6 \mathrm{~mL} / \mathrm{min}$, with the UV detector set at $330 \mathrm{~nm}$ and an injection volume of $10 \mu \mathrm{L}$. Calibration graphs were plotted showing a linear relationship between concentrations versus peak areas for the reference compound. The attribution of the chromatographic peak was based on the retention times of the single compound and confirmed by comparison with the isolated standard. Under our working conditions, the mean of retention time for ISQ was $41.98 \mathrm{~min}$. The concentration of the ISQ was calculated from the experimental peak area by analytical interpolation on a standard calibration line. The limit of quantification (LOQ) of $1.25 \mathrm{~g} / \mathrm{mL}$ for EETM was determined using signal-to-noise ratio.

Electrospray Ionization Fourier Transform Ion Cyclotron Resonance Mass Spectrometry (ESI(+)-FT-ICRMS)

The ESI(+)-FT-ICR MS analysis was performed using a micrOTOF hybrid quadrupole time-of-flight esquire 3000 plus mass spectrometer (Bruker Daltonics, USA) equipped with an Apollo II electrospray ion source in positive ion mode. For acquisition of mass spectra, ions were selected using an isolation width of $\pm 4 \mathrm{Da}$ and fragmented using nitrogen as the collision gas with collision energies in the range of $10-30 \mathrm{eV}$. The eluted compounds in methanol/water 1:1 (v/v) were analyzed in positive ion mode with the following instrument settings: nebulizer gas, $1.6 \mathrm{bar}$; dry gas, nitrogen, $4 \mathrm{~L} / \mathrm{min}, 180^{\circ} \mathrm{C}$; capillary, $-5500 \mathrm{~V}$; end plate offset, $-500 \mathrm{~V}$; funnel $1 \mathrm{RF}, 200 \mathrm{Vpp}$; funnel $2 \mathrm{RF}, 200 \mathrm{Vpp}$; insource CID energy, $0 \mathrm{~V}$; hexapole RF, $100 \mathrm{Vpp}$; quadrupole ion energy, $5 \mathrm{eV}$; collision gas, argon; collision energy, 10 eV; collision RF 200/400 Vpp (timing 50/50); transfer time, $70 \mu \mathrm{s}$; prepulse storage, $5 \mu \mathrm{s}$; pulser frequency, $10 \mathrm{kHz}$. The calibration was performed using a Cole Palmer syringe pump connected to the interface, passing a solution of sodium acetate cluster containing $5 \mathrm{mM}$ sodium hydroxide in a sheath liquid of $0.2 \%$ acetic acid in water/ isopropanol 1:1 (v/v)

\section{Nuclear magnetic resonance (NMR) measurements}

${ }^{1} \mathrm{H}$ NMR spectra were recorded at room temperature on a Bruker 300 spectrometer (Institute of Chemistry, UFMS, Brazil), 10\% in Acetone- $\mathrm{D}_{6}$ solution at $298 \mathrm{~K}$ operating at 300.132 . Data processing was carried out on a Solaris workstation. The ${ }^{1} \mathrm{H}$ NMR parameters were as follows: spectral width, $4789.27 \mathrm{~Hz}$; data points, $64 \mathrm{k}$, zero-filled to $64 \mathrm{k}$; acquisition time, $6.84 \mathrm{~s}$ and digital resolution, $0.07 \mathrm{~Hz}$. Spectral widths of $4789.27 \mathrm{~Hz}$ were used for ${ }^{1} \mathrm{H}$. The ${ }^{1} \mathrm{H}$ chemical shifts are given on the $\delta$ scale $(\mathrm{ppm})$ and were referenced to internal Acetone; coupling constants $(J)$ are reported in hertz $(\mathrm{Hz})$. The abbreviations $\mathrm{s}, \mathrm{d}$, and $\mathrm{m}$ were used for singlet, doublet, and multiplet, respectively.

\section{Pharmacological studies}

Animals

Male Wistar rats (250-280 g) were obtained by Federal University of Paraná (UFPR, Curitiba-PR, Brazil), and were kept in ligth- and temperature -controlled room (12-h light/dark cycle; $\left.22 \pm 2^{\circ} \mathrm{C}\right)$ with ad libitum access to food and water. All experimental protocols were previously approved by the Institutional Ethics Committee of the UFPR (authorization number 240) and were performed in accordance with international standards and ethical guidelines on animal welfare.

\section{Induction of renovascular hypertension (2K1C Goldblatt model)}

The Goldblatt model of hypertension was induced according to procedure described. ${ }^{16}$ Initially, rats were anesthetized with ketamine $(100 \mathrm{mg} / \mathrm{kg})$ and xylazine $(20 \mathrm{mg} / \mathrm{kg})$ by intraperitoneal route. The left renal artery was exposed by retroperitoneal incision and dissected. A silver clip (lumen of $0.22 \mathrm{~mm}$ ) was placed around the artery for partial occlusion; in negative control animals (SHAM operated) the artery was not clipped. After 30 days, the systolic blood pressure (SBP) was measured using the tail-cuff method. Only hypertensive rats (SBP above $145 \mathrm{~mm} \mathrm{Hg}$ ) were used in the experiments.

\section{Experimental design}

Three weeks after hypertension induction, animals were divided into 12 groups ( $n=5$; six groups to studies on renal function and six groups to hemodynamic study) and submitted to the following treatments, once a day (by gavage), during 30 days. Two SHAM operated groups were orally treated with filtered water (vehicle) and defined as negative control. Two hypertensive groups were orally treated with filtered water (vehicle) and defined as positive control. Another six groups of $2 \mathrm{~K} 1 \mathrm{C}$ rats received $\operatorname{EETM}(3,30$ and $300 \mathrm{mg} / \mathrm{kg})$. Finally, two additional groups of rats received furosemide (FURO; $25 \mathrm{mg} / \mathrm{kg}$ ) or captopril (CAP; $60 \mathrm{mg} / \mathrm{kg}$ ).

\section{Studies on renal function}

\section{Diuretic activity}

The diuretic activity was assessed according to methods previously described with some modifications. ${ }^{17}$ Rats were food-deprived overnight $(12 \mathrm{~h})$. On the thirtieth day of treatment all animals received an oral load of isotonic saline $(0.9 \% \mathrm{NaCl}, 5 \mathrm{~mL} / 100 \mathrm{~g})$ to impose a controlled water and salt balance. Immediately after treatment, rats were placed in metabolic cages. Urine was collected and its volume was recorded for $8 \mathrm{~h}$ (expressed as $\mathrm{mL} / 100 \mathrm{~g}$ of body weight). At the end of the experimental period, animals were euthanized (by decapitation) and blood was collected for biochemical analysis. 
Junior et al.: Cardiorenal protective effects of Tropaeolum majus L.

\section{Samples collection and storage}

Plasma and serum were obtained by centrifugation $(1500 \mathrm{~g}, 10 \mathrm{~min}$, $4^{\circ} \mathrm{C}$ ), and stored at $-80^{\circ} \mathrm{C}$ until analyses. Kidneys and hearts were excised, cleaned and weighed. Atria and right ventricle were then removed and the remaining left ventricle was weighed. The renal, heart, and the left ventricle indexes were calculated by dividing the absolute weight of these organs by the body weight of animals on the day of the euthanasia.

\section{Plasma and urine analytical procedures}

The urinary and plasmatic $\mathrm{Na}^{+}$and $\mathrm{K}^{+}$levels were quantified by flame photometry (Quimis model Q398112). Urinary $\mathrm{Cl}^{-}$and $\mathrm{HCO}_{3}$ concentrations were quantified by titration. $\mathrm{pH}$ and conductivity were directly determined on fresh urine samples using Q400MT pH meter and Q795M2 conductivity meter (Quimis Instruments, Brazil), respectively. Density was estimated by weighing using Mettler AE163 ( $\pm 0.1 \mathrm{mg}$ ) analytical scale on urine volume measured using Nichiryo micropipette. Total plasma protein, urea and creatinine levels were determined by enzymatic method for automated analyzer BM/Hitachi 912 (Cobas Mira, Roche, Indianapolis, USA).

\section{Hemodynamic study \\ Direct blood pressure, heart rate, and renal cortical blood flow measurement}

At the end of experimental period, 2K1C rats were anesthetized with ketamine $(100 \mathrm{mg} / \mathrm{kg})$ and xylazine $(20 \mathrm{mg} / \mathrm{kg})$, intramuscularly administered and supplemented at 45 to $60 \mathrm{~min}$ intervals. Animals were allowed to spontaneously breathe through a tracheotomy. The left carotid artery was cannulated and connected to a pressure transducer coupled to a PowerLab recording system (Chart, v 4.1 ; all from ADI Instruments; Castle Hill, Australia) to record both mean arterial pressure (MAP) and heart rate (HR). For measuring renal cortical blood flow (RCBF) a standard plastic tube (DP2b, Moor Instruments) was placed on the ventral surface of the contralateral not clipped kidney (renal capsule below $2 \mathrm{~mm}$ ) according to previous methods. ${ }^{18}$ After $15 \mathrm{~min}$ for stabilization of the surgical procedure, changes in MAP, HR, and RCBF were recorded for $30 \mathrm{~min}$. At the end of the experiments, animals were euthanized with an overdose of thiopental (over $40 \mathrm{mg} / \mathrm{kg}$, i.v.).

\section{Evaluation of mechanisms involved in the renal and cardioprotective effects of EETM} Effects on the renin-angiotensin system

ACE activity was determined by indirect fluorimetry as previously described. ${ }^{19}$ For this, serum samples $(10 \mu \mathrm{L})$ were incubated for $15 \mathrm{~min}$ at $37^{\circ} \mathrm{C}$ with $490 \mu \mathrm{L}$ of assay solution (composition: $\mathrm{NaCl} 0.9 \mathrm{M}$ and Hip-His-Leu at $5 \mathrm{mM}$ in $0.4 \mathrm{M}$ sodium borate buffer, $\mathrm{pH}$ 8.3) The reaction was stopped by addition of $1.2 \mathrm{~mL}$ of $\mathrm{NaOH}(0.34 \mathrm{~N})$. The production of His-Leu was measured fluorometrically (365 nm excitation and 495 emission, Aminco Model J4-7461 fluoromonitor, American Instrument Co., Silver Springs, MD) after the addition of $100 \mu \mathrm{L}$ of o-phthaldialdehyde $(20 \mathrm{mg} / \mathrm{mL}$ in methanol), and $200 \mu \mathrm{L}$ of $\mathrm{HCl}(3 \mathrm{~N})$, followed by centrifugation $(800 \mathrm{~g}, 5 \mathrm{~min})$ at room temperature. To correct intrinsic fluorescence of plasma, time-zero blank samples were prepared by adding plasma after $\mathrm{NaOH}$ treatment. In addition, aldosterone levels were measured by Enzyme Linked Immunosorbent Assay (ELISA, Immuno-Biological Laboratories, Inc). All measurements were made in triplicate.

\section{Evaluation of serum lipid peroxidation (TBARS)}

Thiobarbituric acid (TBARS) levels were measured using commercial assay kits (Nanjing Jiancheng Institute, Nanjing, China) on a spectrophotometer (DU7400, Beckman Co., Fullerton, CA, USA), according to manufacturer's instruction. Absorbance was read at $535 \mathrm{~nm}$ in a microplate reader, and the concentration of TBARS was expressed as mmol/L.

\section{Determination of nitrate/nitrite serum (NOx)}

The plasma nitrite concentration was determined by reducing nitrate enzymatically using the enzyme nitrate reductase, as previously described. ${ }^{20}$ Plasma samples were deproteinized with zinc sulfate $(30 \mathrm{mmol})$ and diluted 1:1 with Milli-Q water. For the conversion of nitrate to nitrite, samples were incubated at $37^{\circ} \mathrm{C}$ for 2 hours in the presence of nitrate reductase expressed in Escherichia coli. After the incubation period, samples were centrifuged ( $800 \mathrm{~g}, 10$ minutes) to remove the bacteria. Then, $100 \mu \mathrm{L}$ of supernatant was mixed with an equal volume of Griess reagent ( $1 \%$ sulfanilamide in $10 \%$ phosphoric acid/ $0.1 \%$ alpha-naphthylethylenediamine in Milli-Q water) in a 96-well plate and read at $540 \mathrm{~nm}$. Standard curves of nitrite and nitrate (0-150 mM) were performed simultaneously.

\section{Statistical analysis}

The results are expressed as mean \pm standard error of the mean (S.E.M.). Statistical analyses were performed using one-way analysis of variance (ANOVA) followed by Bonferroni's test. $p$-value less than 0.05 was considered statistically significant. Graphs were drawn and statistical analyses were performed using GraphPad Prism software version 5.0 for Mac OS X (GraphPad Software, Inc., La Jolla, CA, USA).

\section{RESULTS}

\section{Sample characterization}

The HPLC-UV fingerprint of the EETM (Figure 1) showed characteristic distributions of the flavonoids, including the ISQ with maxima absorption at 257 and $352 \mathrm{~nm}$ and identified by comparison with data found in the literature. ${ }^{21}$ These results were confirmed by ${ }^{1} \mathrm{H}$ NMR analysis using isolated standard of ISQ and the structures were unequivocally confirmed by co-injection of authentic standards and identified by retention values. The HPLC quantitative method was validated for ISQ. ${ }^{22}$ The content of this compound in the EETM was $2.10 \%$, equation of measurements was $\mathrm{Y}=9 \times 10^{-5} \mathrm{X}-0.6655$ and $\mathrm{R}^{2}=0.9973$.

${ }^{1} \mathrm{H}$ NMR (300 MHz, Acetone-D $)$ : (ppm) $3.347(m, 3 \mathrm{H}), 3.443(m, 4 \mathrm{H})$, $4.184(s, 1 \mathrm{H}), 4.276(s, 1 \mathrm{H}), 5.133(s, 1 \mathrm{H}), 5.234(d, J=7.20 \mathrm{~Hz}, 2 \mathrm{H})$, $6.276(d, J=1.80,1 \mathrm{H}), 6.506(d, J=2.1,1 \mathrm{H}), 6.925(s, 1 \mathrm{H}), 6.953(s, 1 \mathrm{H})$, $7.574(m, 2 \mathrm{H}), 8.014(d, J=1.80 \mathrm{~Hz}, 1 \mathrm{H}), 12.362(s, 1 \mathrm{H})$.

ESI(+)-FT-ICR MS (Figure 2) provides $\mathrm{M}_{\text {of }} \mathrm{C}_{21} \mathrm{H}_{20} \mathrm{O}_{12}$, where ions $[\mathrm{M}+\mathrm{H}]^{+}$, $[\mathrm{M}+\mathrm{Na}]^{+},[\mathrm{M}+\mathrm{Cl}]^{+}$and $[\mathrm{M}+\mathrm{K}]^{+}$with $\mathrm{m} / \mathrm{z}$ of $465.0930,487.0178$, 499.0533 and 503.0543, with mass error $=-0.33,-0.24,-0.34$ and -0.22 ppm, respectively, and base peak of 350.1470 were identified.

\section{EETM induces sustained diuretic, natriuretic, and potassium-sparing} effects after 30 days of oral treatment

In $2 \mathrm{~K} 1 \mathrm{C}$ animals, treatment with EETM (300 mg/kg) was able to induce a significant increase in diuresis. The final urine volume $(8 \mathrm{~h})$ for rats treated with EETM $(300 \mathrm{mg} / \mathrm{kg})$ was $5.2 \pm 0.6$ vs. $2.6 \pm 0.8 \mathrm{~mL} / 100 \mathrm{~g} / 8 \mathrm{~h}$ $(\mathrm{p}<0.05)$ for positive control animals, being similar to values obtained after treatment with furosemide $(5.1 \pm 0.7 \mathrm{~mL} / 100 \mathrm{~g} / 8 \mathrm{~h})$ or SHAM operated animals $(4.7 \pm 0.5 \mathrm{~mL} / 100 \mathrm{~g} / 8 \mathrm{~h})$. Moreover, a significant increase in urinary conductivity was observed in animals treated with EETM (300 $\mathrm{mg} / \mathrm{kg}$ ) and furosemide, while urinary density was significantly reduced in these animals (Table 1).

Animals treated with EETM (300 mg/kg) and furosemide showed high contents of $\mathrm{Na}^{+}$in urine when compared to positive controls (Table 2). The contents of urinary $\mathrm{Na}^{+}$in animals treated with EETM and furosemide were $137 \pm 3.0$ and $140 \pm 4.2 \mathrm{mmol} / \mathrm{L}$, respectively, while in positive control group were $95 \pm 4.3 \mathrm{mmol} / \mathrm{L}(\mathrm{p}<0.05)$.

All animals treated with EETM showed an interesting potassium-sparing effect at all doses used (Table 2), while furosemide excreted large amounts of this ion (negative control: $29 \pm 7.2 \mathrm{mmol} / \mathrm{L}$; positive control: 
$30 \pm 5.9 \mathrm{mmol} / \mathrm{L}$; furosemide: $59 \pm 3.2$; EETM 300: $24 \pm 2.9$ ). All other parameters did not show statistically significant differences when compared to the control groups.

\section{Prolonged treatment with EETM prevents changes in serum markers of} renal function in $2 \mathrm{~K} 1 \mathrm{C}$ rats

Animals treated with EETM at dose of $300 \mathrm{mg} / \mathrm{kg}$ showed significant renoprotective effect after 30 days of treatment. Untreated $2 \mathrm{~K} 1 \mathrm{C}$ rats (positive control) showed significant increase in serum urea and creatinine, associated with reductions in total protein concentration (Table 3 ). These changes were not observed in animals treated with EETM (300 $\mathrm{mg} / \mathrm{kg}$ ). Moreover, serum sodium and potassium levels were not affected by any treatment performed.

\section{EETM treatment prevents heart hypertrophy induced by renovascular hypertension}

The effects of 30-day oral administration of T. majus extract on cardiac and renal indices are shown in Table 4 . Heart and left ventricle weight ratio were significantly reduced in rats treated with EETM $(300 \mathrm{mg} / \mathrm{kg})$ when compared with the positive control (HW/BW ratio: positive control: $2.93 \pm 0.08$ vs. EETM 300: $2.45 \pm 0.07$ p <0.05; LVW/BW ratio: control $2.13 \pm 0.07$ vs. EETM 300: $1.79 \pm 0.08 \mathrm{p}<0.05)$. All other parameters did not show any significant differences among experimental groups.

\section{Prolonged treatment with EETM prevents chronic blood pressure elevation in $2 \mathrm{~K} 1 \mathrm{C}$ rats}

Basal MAP recorded in SHAM operated and Goldblatt hypertensive rats (positive control) after the 15-min period allowed for stabilization was $93 \pm 3.81$ and $138 \pm 4.45 \mathrm{~mm} \mathrm{Hg}$, respectively. The oral administration of EETM caused a dose dependent antihypertensive effect (Figure 3A), reducing MAP levels to $122 \pm 4.78$ and $99 \pm 3.93 \mathrm{~mm} \mathrm{Hg}$ (100 and 300 $\mathrm{mg} / \mathrm{kg}$, respectively), with minor effects on heart rate (data not shown). In addition, an important increase in renal cortical blood flow was observed after prolonged EETM administration (100 and $300 \mathrm{mg} / \mathrm{kg}$ ). Data have shown increase ranging from 15 to $30 \%$, respectively, when compared to groups treated with vehicle alone (Figure 3B).

\section{EETM treatment significantly reduces plasma ACE activity, serum aldosterone, and oxidative stress in $2 \mathrm{~K} 1 \mathrm{C}$ rats}

The effects of 30-day oral treatment with EETM on ACE activity and serum aldosterone levels are shown in Figure 4 A-B. The plasmatic ACE activity after treatment with EETM (100 and $300 \mathrm{mg} / \mathrm{kg}$ ) was reduced by $14 \pm 2$ and $40 \pm 6 \%$, respectively, when compared to positive control group. As expected, captopril reduced the ACE activity around $56 \%$. Similarly, EETM $(300 \mathrm{mg} / \mathrm{kg})$ and captopril administration reduced aldosterone levels by $32 \pm 6 \%$ and $45 \pm 3 \%$, respectively.

The antioxidant effect of EETM was estimated by TBARS and nitrite measurement (a marker of nitric oxide bioavailability). In $2 \mathrm{~K} 1 \mathrm{C}$ rats, EETM (300 mg/kg) was able to increase nitrite levels by approximately $78 \%$ (Figure 4C). Additionally, TBARS were reduced by approximately $52 \%$ when compared to positive control group (Figure 4D).

\section{DISCUSSION}

Currently, hypertension appears as a major public health problem worldwide, and when not properly controlled, can catalyze the emergence of various kidney and heart diseases such as stroke, renal failure and heart attack. ${ }^{1}$ The available therapeutic arsenal for the treatment of hypertension is multivariable and highly effective, however, in various countries, the control of this disease is inappropriate, and the major reason is the poor adherence to antihypertensive medications. ${ }^{23}$ Older age, living alone, and perception related to treatment control were significant independent factors associated with better medication adherence. Moreover, cultivating positive beliefs that hypertension is controlled by

Table 1: Effect of 30-days oral administration of Tropaeolum majus L. extract on urinary volume, $\mathrm{pH}$, conductivity and density

\begin{tabular}{ccccc}
\hline Group & $\begin{array}{c}\text { Urine volume } \\
(8 \mathrm{~h} / 100 \mathrm{~g})\end{array}$ & $\mathrm{pH}$ & $\begin{array}{c}\text { Conductivity } \\
(\mathrm{mS} / \mathrm{cm})\end{array}$ & $\begin{array}{c}\text { Density } \\
(\mathrm{g} / \mathrm{mL})\end{array}$ \\
\hline SHAM & $4.7 \pm 0.5$ & $6.1 \pm 0.2$ & $14.5 \pm 0.1$ & $1014 \pm 0.6$ \\
Positive control & $2.6 \pm 0.8^{\mathrm{b}}$ & $6.4 \pm 0.3$ & $15.1 \pm 0.2$ & $1016 \pm 0.7$ \\
FURO $(25 \mathrm{mg} / \mathrm{kg})$ & $5.1 \pm 0.7^{\mathrm{a}}$ & $6.5 \pm 0.2$ & $17.5 \pm 0.1^{\mathrm{ab}}$ & $1007 \pm 0.6^{\mathrm{a}}$ \\
EETM $(3 \mathrm{mg} / \mathrm{kg})$ & $3.1 \pm 0.6$ & $6.4 \pm 0.4$ & $14.7 \pm 0.2$ & $1015 \pm 0.5$ \\
EETM $(30 \mathrm{mg} / \mathrm{kg})$ & $2.9 \pm 0.5$ & $6.3 \pm 0.3$ & $15.4 \pm 0.1$ & $1014 \pm 0.9$ \\
EETM $(300 \mathrm{mg} / \mathrm{kg})$ & $5.2 \pm 0.6^{\mathrm{a}}$ & $6.4 \pm 0.4$ & $17.3 \pm 0.2^{\mathrm{ab}}$ & $1008 \pm 0.6^{\mathrm{a}}$ \\
\hline
\end{tabular}

Values are expressed as mean \pm S.E.M. in comparison to the positive control (a; $\mathrm{p}<0.05$ ) or SHAM operated rats $(\mathrm{b} ; \mathrm{p}<0.05)$ using one-way ANOVA followed by Bonferroni's test. FURO: furosemide. EETM: ethanolic extract of T. majus.

Table 2: Effect of 30-days oral administration of Tropaeolum majus L. extract on urinary electrolyte excretion

\begin{tabular}{|c|c|c|c|c|c|c|c|c|}
\hline \multirow{2}{*}{ Group } & \multirow{2}{*}{$\begin{array}{c}\mathrm{Na}^{+} \\
(\mathrm{mmol} / \mathrm{L})\end{array}$} & \multirow{2}{*}{$\begin{array}{c}\mathrm{K}^{+} \\
(\mathrm{mmol} / \mathrm{L})\end{array}$} & \multirow{2}{*}{$\begin{array}{c}\mathrm{Cl}^{-} \\
(\mathrm{mmol} / \mathrm{L})\end{array}$} & \multirow{2}{*}{$\begin{array}{c}\mathrm{HCO}_{3}^{-} \\
(\mathrm{mmol} / \mathrm{L})\end{array}$} & \multicolumn{4}{|c|}{ Saluretic index ${ }^{b}$} \\
\hline & & & & & $\mathrm{Na}^{+}$ & $\mathbf{K}^{+}$ & $\mathrm{Cl}^{-}$ & $\mathrm{HCO}_{3}^{-}$ \\
\hline SHAM & $110 \pm 4.5$ & $29 \pm 7.2$ & $120 \pm 14$ & $27 \pm 2.0$ & & & & \\
\hline Positive control & $95 \pm 4.3$ & $30 \pm 5.9$ & $122 \pm 10$ & $25 \pm 2.1$ & - & - & - & - \\
\hline FURO $(25$ mg/kg) & $140 \pm 4.2^{\mathrm{ab}}$ & $59 \pm 3.2^{\mathrm{ab}}$ & $155 \pm 15$ & $30 \pm 3.1$ & 1.49 & 1.96 & 1.27 & 1.20 \\
\hline $\operatorname{EETM}(3 \mathrm{mg} / \mathrm{kg})$ & $90 \pm 6.5$ & $33 \pm 6.1$ & $115 \pm 16$ & $24 \pm 1.7$ & 0.97 & 1.20 & 0.94 & 0.96 \\
\hline $\operatorname{EETM}(30 \mathrm{mg} / \mathrm{kg})$ & $100 \pm 5.1$ & $28 \pm 4.2$ & $112 \pm 19$ & $28 \pm 2.1$ & 1.05 & 0.93 & 0.91 & 1.12 \\
\hline $\operatorname{EETM}(300 \mathrm{mg} / \mathrm{kg})$ & $137 \pm 3.0^{\mathrm{ab}}$ & $24 \pm 2.9$ & $148 \pm 19$ & $22 \pm 1.6$ & 1.44 & 0.80 & 1.21 & 0.88 \\
\hline
\end{tabular}

Values are expressed as mean \pm S.E.M. in comparison to the positive control ( $\mathrm{a} ; \mathrm{p}<0.05)$ or SHAM operated rats $(\mathrm{b} ; \mathrm{p}<0.05)$ using one-way ANOVA followed by Bonferroni's test. Saluretic index $=\mathrm{mmol} / \mathrm{L}$ problem group $/ \mathrm{mmol} / \mathrm{L}$ control group. FURO: furosemide. EETM: ethanolic extract of T. majus. 


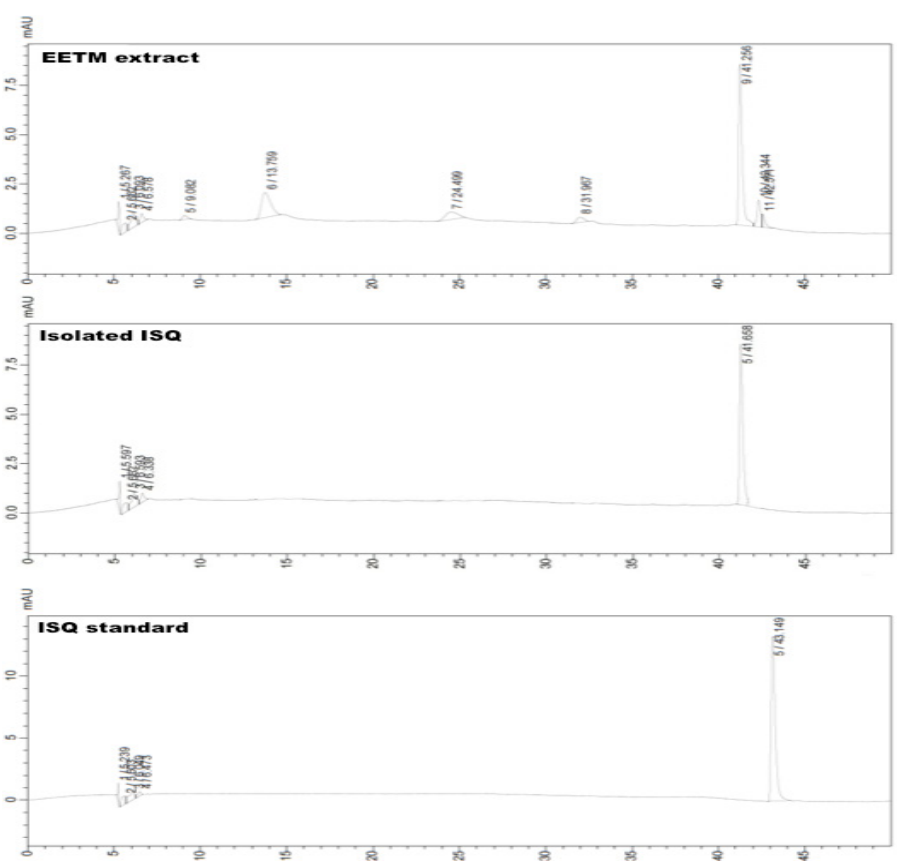

Figure 1: HPLC chromatograms of EETM extract, isolated ISQ and ISQ standard.
Table 3: Effect of prolonged oral administration of Tropaeolum majus $\mathrm{L}$. extract on serum total protein, urea, creatinine, sodium and potassium of $2 \mathrm{~K} 1 \mathrm{C}$ rats

\begin{tabular}{|c|c|c|c|c|c|}
\hline Group & $\begin{array}{c}\text { Total } \\
\text { protein } \\
(\mathrm{g} / \mathrm{L})\end{array}$ & $\begin{array}{c}\text { Urea } \\
\text { (mg/dL) }\end{array}$ & $\begin{array}{l}\text { Creatinine } \\
\text { (mg/dL) }\end{array}$ & $\begin{array}{l}\text { Sodium } \\
(\mathrm{mmol} / \mathrm{L})\end{array}$ & $\begin{array}{l}\text { Potassium } \\
\text { (mmol/L) }\end{array}$ \\
\hline SHAM & $6.0 \pm 0.5$ & $28 \pm 3.9$ & $0.7 \pm 0.2$ & $144 \pm 4.4$ & $5.8 \pm 1.5$ \\
\hline $\begin{array}{l}\text { Positive } \\
\text { control }\end{array}$ & $3.4 \pm 0.2^{\mathrm{b}}$ & $59 \pm 3.8^{\mathrm{b}}$ & $1.6 \pm 0.2^{\mathrm{b}}$ & $141 \pm 3.8$ & $5.6 \pm 2.0$ \\
\hline $\begin{array}{c}\text { FURO } \\
(25 \mathrm{mg} / \\
\mathrm{kg})\end{array}$ & $3.6 \pm 0.2^{b}$ & $47 \pm 2.3^{b}$ & $1.4 \pm 0.3^{\mathrm{b}}$ & $143 \pm 2.3$ & $6.2 \pm 1.9$ \\
\hline $\begin{array}{c}E E T M \\
(3 \mathrm{mg} / \\
\mathrm{kg})\end{array}$ & $3.1 \pm 0.3^{b}$ & $50 \pm 2.7^{b}$ & $1.5 \pm 0.2^{b}$ & $141 \pm 5.7$ & $5.9 \pm 1.8$ \\
\hline $\begin{array}{c}\text { EETM } \\
(30 \mathrm{mg} / \\
\mathrm{kg})\end{array}$ & $4.0 \pm 0.2^{\mathrm{b}}$ & $42 \pm 4.3^{b}$ & $1.3 \pm 0.3^{b}$ & $144 \pm 4.3$ & $6.1 \pm 1.5$ \\
\hline $\begin{array}{c}\text { EETM } \\
(300 \\
m g / k g)\end{array}$ & $5.6 \pm 0.3^{a}$ & $31 \pm 2.3^{\mathrm{a}}$ & $0.5 \pm 0.1^{\mathrm{a}}$ & $149 \pm 6.3$ & $6.0 \pm 2.0$ \\
\hline
\end{tabular}

Values are expressed as mean \pm S.E.M. in comparison to the positive control (a; $\mathrm{p}$ $<0.05$ ) or SHAM operated rats ( $\mathrm{b} ; \mathrm{p}<0.05)$ using one-way ANOVA followed by Bonferroni test. FURO: Furosemide. EETM: ethanolic extract of T. majus

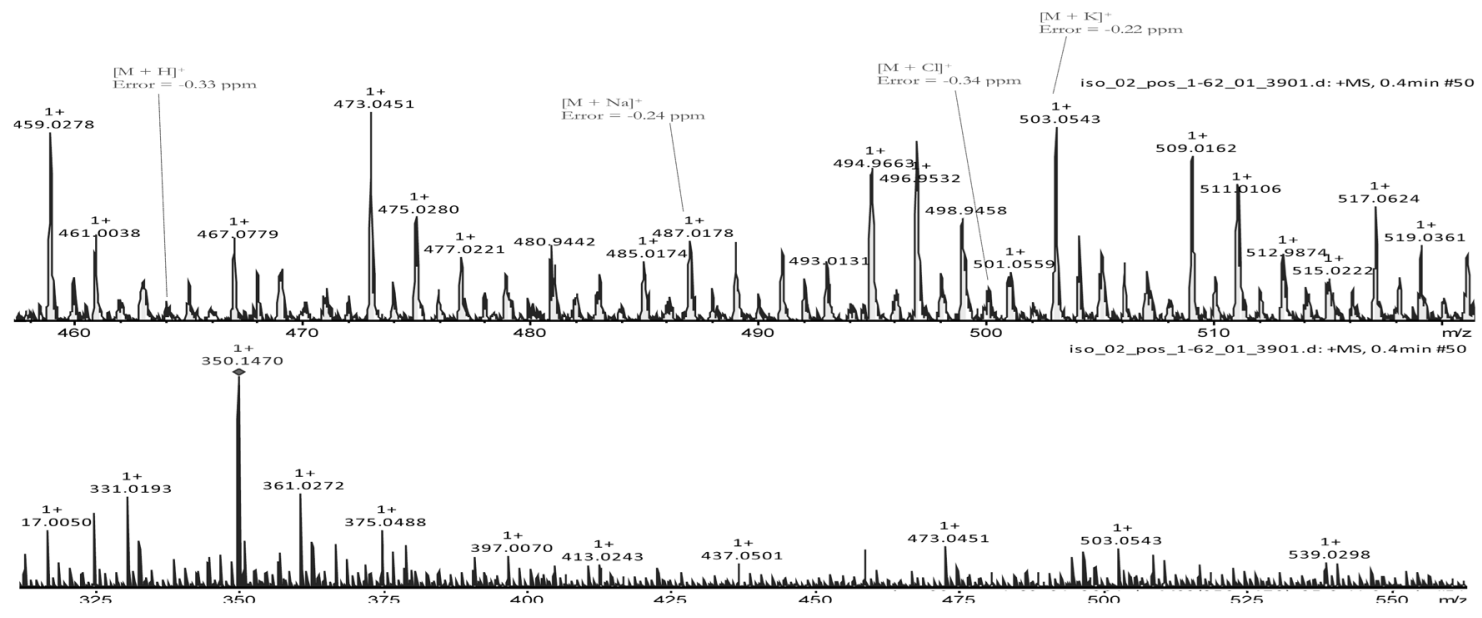

Figure 2: High-resolution mass spectrum data for isolated ISQ.

Table 4: Effect of chronic oral administration of Tropaeolum majus L. extract on cardiac and renal indices of $2 \mathrm{~K} 1 \mathrm{C}$ rats

\begin{tabular}{ccccc}
\hline Group & HW/BW ratio & LVW/BW ratio & CKW/BW ratio & SKW/BW ratio \\
\hline SHAM & $2.20 \pm 0.05$ & $1.60 \pm 0.06$ & $3.48 \pm 0.21$ & $1.61 \pm 0.31$ \\
Positive control & $2.93 \pm 0.08^{\mathrm{b}}$ & $2.13 \pm 0.07^{\mathrm{b}}$ & $3.51 \pm 0.12$ & $1.73 \pm 0.30$ \\
CAP $(60 \mathrm{mg} / \mathrm{kg})$ & $2.40 \pm 0.06^{\mathrm{b}}$ & $1.69 \pm 0.06^{\mathrm{a}}$ & $3.44 \pm 0.22$ & $1.59 \pm 0.33$ \\
$\operatorname{EETM}(3 \mathrm{mg} / \mathrm{kg})$ & $2.89 \pm 0.07^{\mathrm{b}}$ & $2.15 \pm 0.08^{\mathrm{b}}$ & $3.41 \pm 0.17$ & $1.55 \pm 0.32$ \\
$\operatorname{EETM}(30 \mathrm{mg} / \mathrm{kg})$ & $2.79 \pm 0.06^{\mathrm{b}}$ & $2.00 \pm 0.07^{\mathrm{b}}$ & $3.54 \pm 0.18$ & $1.70 \pm 0.26$ \\
$\operatorname{EETM}(300 \mathrm{mg} / \mathrm{kg})$ & $2.45 \pm 0.07^{\mathrm{ab}}$ & $1.79 \pm 0.08^{\mathrm{a}}$ & $3.40 \pm 0.20$ & $1.57 \pm 0.35$ \\
\hline
\end{tabular}

Values are expressed as mean \pm S.E.M. in comparison to the positive control $(\mathrm{a} ; \mathrm{p}<0.05)$ or SHAM operated rats ( $\mathrm{b} ; \mathrm{p}<0.05)$ using one-way ANOVA followed by Bonferroni's test. BW: body weight; CAP: captopril; CKW: contralateral kidney weight; EETM: ethanolic extract of T. majus; HW: heart weight; LVW: left ventricle weight; SKW: stenotic kidney weight. 
treatment is one of the most appropriate ways for adequate control of this pathology. ${ }^{24}$

In recent years, several studies have been conducted to identify alternative therapies derived from natural products for use as an adjunct to conventional drug therapy in hypertension treatment. This initiative could encourage the improvement of adherence to pharmacological treatment, offering a product with great popular appeal and pharmacological effects complementary to conventional therapies. ${ }^{25-31}$

In this study, it was shown for the first time that prolonged treatment with an ethanol extract obtained from T. majus is able to prevent the evolution of renovascular hypertension in $2 \mathrm{~K} 1 \mathrm{C}$ rats, showing a significant reno-and cardioprotective effect. According to previous data, the renin-angiotensin system (RAS) played a prominent role in the oxidative stress and renovascular hypertension..$^{32}$ Since RAS is clearly involved in the development of this pathology, antihypertensive agents such as
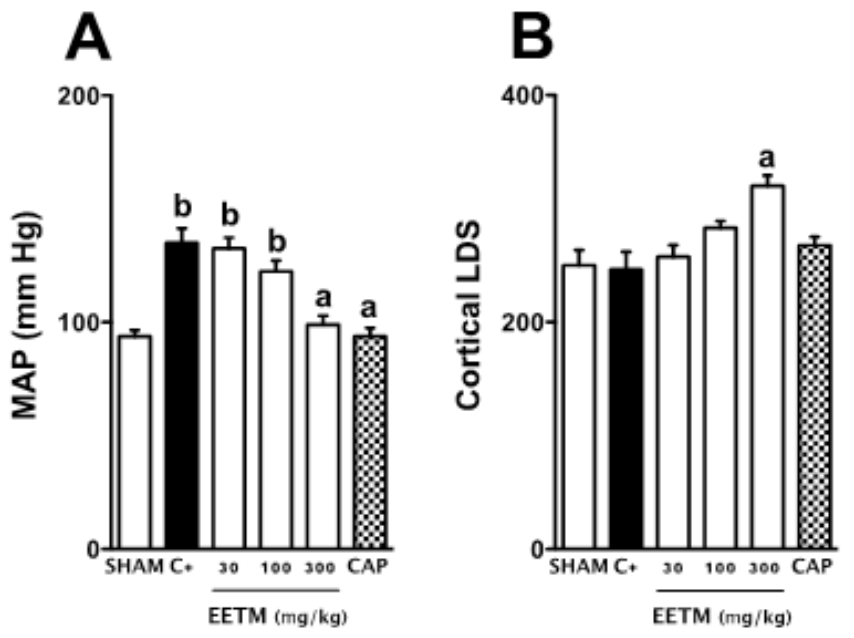

Figure 3: Tropaeolum majus L. extract (EETM) induced hypotension (A) and increase renal cortical blood flow (B) in Goldblatt hypertensive rats. The antihypertensive and renal cortical blood flow effects were measured for 45 minutes after 30 -days of treatment. Values are expressed as mean \pm S.E.M. in comparison to the positive control $(a ; p<0.05)$ or SHAM operated rats $(b ; p$ $<0.05$ ) using one-way ANOVA followed by Bonferroni's test. CAP: captopril; LDS: laser doppler scale; MAP: mean arterial pressure.
ACE inhibitors are the first line treatment of these conditions. ${ }^{33,34}$ In fact, as the EETM showed prolonged ACE inhibitory activity similar to captopril, an important reduction in MAP and serum aldosterone were observed, leading to significant reduction of cardiac hypertrophy and improvement of renal function.

Another fact that drew attention in this work is related to the sustained diuretic effect induced by EETM. Prolonged EETM administration was able to increase the urine volume and sodium excretion in a manner very similar to furosemide, with the advantage of not excreting significant amounts of potassium. This effect can also be directly or indirectly influenced by ACE inhibition mainly due to increased bradykinin bioavailability. Recent studies have shown that classic ACE inhibitors can cause acute diuretic and natriuretic effect directly influenced by a reduction in the bradykinin metabolism, with consequent release of prostaglandins and nitric oxide in the renal arterioles, which may increase the RCBF and glomerular filtration rate, inducing diuretic effect. ${ }^{35}$ In fact, we show by direct measurement of RCBF that the EETM could increase the renal blood flow, indicating a likely vasodilator effect and a significant increase in hydrostatic pressure in the renal arterioles, which directly increases glomerular filtration rate and the urine output.

Currently, it is known that ISQ, the main active metabolite of T. majus, has a wide range of important cardiovascular effects including, diuretic, ${ }^{13}$ antihypertensive, ${ }^{9,36}$ antiatherosclerotic ${ }^{37}$ and antidiabetic. ${ }^{38}$ It has been recently reported that ISQ-induced acute hypotension is an event dependent on the inhibition of angiotensin II generation by ACE. ${ }^{9}$ Moreover, it was also suggested that mechanisms by which ISQ exerts its diuretic effect on SHR rats are mainly related to ACE inhibition, increased bioavailability of bradykinin, prostaglandins, and nitric oxide. ${ }^{13} \mathrm{We}$ also believe that ISQ can play a major role in this effect, however it is likely that the effect obtained with EETM comes from a complex interaction between different secondary metabolites acting as a powerful phytocomplex.

\section{CONCLUSION}

This study has brought new scientific evidence of preclinical efficacy of $T$. majus as a reno-and cardioprotective agent. In addition, it presents important evidence on the role of ACE inhibition in these effects, opening up the prospect that EETM can be converted into an herbal preparation in the future.

\section{ACKNOWLEDGEMENT}

This work was supported by grants from the Fundação de Apoio ao Desenvolvimento do Ensino, Ciência e Tecnologia do Estado de Mato
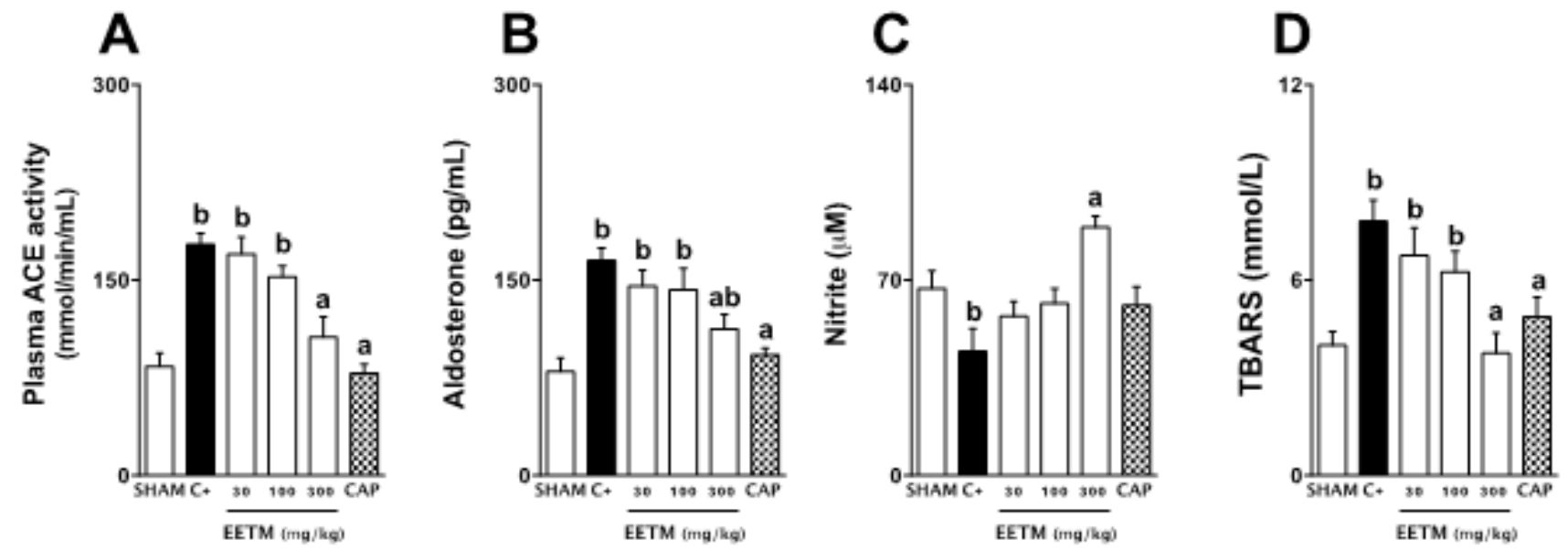

Figure 4: Tropaeolum majus L. extract (EETM) inhibit serum ACE activity (A), reduce levels of aldosterone (B), increases serum nitrate (C), and protect against lipid peroxidation (D) in 2K1C rats. The serum samples were obtained after 30-days of treatment. Values are expressed as mean \pm S.E.M. in comparison to the positive control $(a ; p<0.05)$ or SHAM operated rats $(b ; p<0.05)$ using one-way ANOVA followed by Bonferroni's test. CAP: Captopril. 
Grosso do Sul (FUNDECT, Brazil, 59/300.046/2015), and Conselho Nacional de Desenvolvimento Científico e Tecnológico (CNPq, Brazil, 449464/2014-8).

\section{Compliance with ethical standards}

Ethical approval All applicable international, national, and/or institutional guidelines for the care and use of animals were followed. The procedures performed in animals were in accordance with the ethical standards of the institution (UFPR).

\section{CONFLICT OF INTEREST}

The authors declare that they have no conflict of interest. This work was supported by grants from the Fundação de Apoio ao Desenvolvimento do Ensino, Ciência e Tecnologia do Estado de Mato Grosso do Sul (FUNDECT, Brazil, 59/300.046/2015), and Conselho Nacional de Desenvolvimento Científico e Tecnológico (CNPq, Brazil, 449464/2014-8).

\section{ABBREVIATION USED}

2K1C: two-kidney, one-clip Goldblatt hypertensive rats; ACE: Angiotensin-converting enzyme; ANOVA: Analysis of variance; CAP: Captopril; EETM: Ethanolic extract obtained from Tropaeoum majus; ESI(+)-FT-ICR MS: Electrospray ionization fourier transform ion cyclotron resonance mass spectrometry; FURO: Furosemide; HPLC: High-performance liquid chromatography; HR: Heart rate; ISQ: Isoquercitrin; LOQ: Limit of quantification; MAP: Mean arterial pressurel; NMR: Nuclear magnetic resonance; NOx: Nitrite/nitrate levels; RAS: Renin-angiotensin system; RCBF: Renal cortical blood flow; SBP: Systolic blood pressure; SEM: Standard error of the mean; SHAM: Placebo surgery; TBARS: Thiobarbituric acid reactive substances; UFMS: Federal University of Mato Grosso do Sul; UFPR: Federal University of Paraná; UNIPAR: Paranaense University; UV: Ultraviolet.

\section{REFERENCES}

1. World Health Organization (WHO). A global brief on hypertension: silent killer, global public health crisis. Geneva. 2013; 1-40.

2. Sposito AC. Emerging insights into hypertension and dyslipidaemia synergies. Eur Heart J. 2004;6:G8-G12. doi: doi.org/10.1016/j.ehjsup.2004.10.003

3. Orekhov AN, Sobenin IA, Korneev NV, Kirichenko TV, Myasoedova VA, Melnichenko AA, et al. Anti-atherosclerotic therapy based on botanicals. Recent Pat Cardiovasc Drug Discov. 2013;8(1):56-66.

4. Conde BE, Rogerio ITS, Siqueira AM, Ferreira MQ, Chedier LM, Pimenta DS. Ethnopharmacology in the vicinity of the botanical garden of the federal university of Juiz De Fora, Brazil. Ethnobotany Res and Applic. 2014;12:91-111. doi: 10.17348/era.12.0.091-111

5. Ferro D. Fitoterapia: conceitos clínicos. Atheneu, São Paulo, 2006.

6. Garcia D, Domingues MV, Rodrigues E. Ethnopharmacological survey among migrants living in the Southeast Atlantic Forest of Diadema, São Paulo, Brazil. $\mathrm{J}$ Ethnobiol Ethnomed. 2010;6(1):1-19. doi: 10.1186/1746-4269-6-29

7. Lykkesfeldt J, Meller BL. Synthesis of Benzylglucosinolate in Tropaeolum majus L. Plant Physiol. 1993;102(2): 609-13.

8. Gry J, Søborg I, Andersson HC. Cucubitacins in plant food. Nordic Council of Ministers: Copenhagen, Denmark, 2006.

9. Gasparotto JA, Gasparotto FM, Lourenço EL Crestani S, Stefanello ME, Salvador MJ, et al. Antihypertensive effects of isoquercitrin and extracts from Tropaeolum majus L.: evidence for the inhibition of angiotensin converting enzyme. J Ethnopharmacol. 2011;134(2):363-72. doi: 10.1016/j.jep.2010

10. De Medeiros JMR, Macedo M, Contancia JP, Nguyen C, Cunningham G, Miles DH Antithrombin activity of medicinal plants of the Azores. J Ethnopharmacol 2000;72(1):157-65. doi: 10.1016/S0378-8741(00)00226-9

11. Goos KH, Albrecht U, Schneider B, Duque AO, Nihi F, Lourenço AC, et al. Efficacy and safety profile of a herbal drug containing nasturtium herb and horseradish root in acute sinusitis, acute bronchitis and acute urinary tract infection in comparison with other treatments in the daily practice/results of a prospective cohort study. J Ethnopharmacol. 2006;56(3):249-57. doi: 10.1055/s0031-1296717

12. GasparottoJA, Boffo MA, Lourenço ELB, StefanelloME, Kassuya CA, MarquesMC. Natriuretic and diuretic effects of Tropaeolum majus (Tropaeolaceae) in rats. Ethnopharmacol. 2009;122(3):517-22. doi: 10.1016/j.jep.2009.01.021

13. Gasparotto JA, Prando TB, Leme T dos S, Gasparotto FM, Lourenço EL, Rattmann YD, et al. Mechanisms underlying the diuretic effects of Tropaeolum majus $L$. extracts and its main component isoquercitrin. J Ethnopharmacol. 2012;141(1):501-9. doi: 10.1016/j.jep.2012.03.018

14. Gomes C, Lourenço EL, Liuti EB et al. Evaluation of subchronic toxicity of the hydroethanolic extract of Tropaeolum majus in Wistar rats. J Ethnopharmacol. 2012;142(2):481-7. doi: 10.1016/j.jep.2012.05.023
15. Lourenço EL, Muller JC, Boareto AC. Screening for in vivo (anti)estrogenic and (anti)androgenic activities of Tropaeolum majus $\mathrm{L}$. and its effect on uterine contractility. J Ethnopharmacol. 2012;141(1):418-23. doi: 10.1016/j.jep.2012.03.004

16. Umar A, Imam G, Yimin W, Kerim P, Tohti I, Berké B, et al. Antihypertensive effects of Ocimum basilicum L. (OBL) on blood pressure in renovascular hypertensive rats. Hypertens Res. 2010;33(7):727-30. doi: 10.1038/hr.2010.64

17. Kau ST, Keddie JR, Andrews D. A method for screening diuretic agents in the rat. J Pharmacol Method. 1984;11(1):67-75

18. Flemming B, Seeliger E, Wronski T, Steer K, Arenz N, Persson PB. Oxygen and renal hemodynamics in the conscious rat. J Am Soc Nephrol. 2000;11(1):18-24.

19. Santos RA, Krieger EM, Greene LJ. An improved fluorometric assay of rat serum and plasma converting enzyme. Hypertension. 1985;7(2):244-52.

20. Schmidt HHHW, Wilke P, Evers B, Böhme E. Enzymatic formation of nitrogen oxides from L-arginine in bovine brain cytosol. Biochem Bioph Res Co. 2003;165(1):278-84. doi: 10.1016/0006-291X(89)91067-X

21. Slimestad R. Flavonoids in buds and young needles of Picea, Pinus and Abies Biochem Syst Ecol. 2003;31(11):1247-55.

22. Gaskell SJ. Electrospray: Principles and practice. J Mass Spectrom 1997;32:677-88

23. Borzecki AM, Oliveria SA, Berlowitz DR. Barriers to hypertension control. Am Heart J. 2005;149:785-94. doi: 10.1016/j.ahj.2005.01.047

24. Marshall IJ, Wolfe CDA, McKevitt C. Lay perspectives on hypertension and drug adherence: systematic reviewof qualitative research. BMJ. 2012;345: e3953. doi: 10.1136/bmj.e3953

25. Brook RD, Jackson EA, Giorgini P, McGowan CL. When and how to recommend 'alternative approaches' in the management of high blood pressure. Am J Med. 2015;128(6):567-70. doi: 10.1016/j.amjmed.2014.12.029

26. Wright $\mathrm{Cl}$, Van-Buren $\mathrm{L}$, Kroner $\mathrm{Cl}$, Koning MMG. Herbal medicines as diuretics: a review of the scientific evidence. J Ethnopharmacol. 2007;114(1):1-31. doi: 10.1016/j.jep.2007.07.023

27. Bachhav SS, Bhutada MS, Patil SP, Sharma KS, Patil SD. Oleanolic Acid Prevents Increase in Blood Pressure and Nephrotoxicity in Nitric Oxide Dependent Type of Hypertension in Rats. Pharmacognosy Res. 2014;7(4):385-92. doi: 10.4103/0974-8490.159575.

28. Fatima N, Pingali U, Pilli R. Evaluation of Phyllanthus emblica extract on cold pressor induced cardiovascular changes in healthy human subjects. Pharmacognosy Res. 2014;6(1):29-35. doi: 10.4103/0974-8490.122914.

29. Jadhav N, Patil CR, Chaudhari KB, Wagh JP, Surana SJ, Jadhav RB. Diuretic and natriuretic activity of two mistletoe species in rats. Pharmacognosy Res. 2010;2(1):50-7. doi: 10.4103/0974-8490.60576.

30. Patel R, Mahobia NK, Gendle R, Kaushik B, Singh SK. Diuretic activity of leaves of Plectranthus amboinicus (Lour) Spreng in male albino rats. Pharmacognosy Res. 2010;2(2):86-8. doi: 10.4103/0974-8490.62956.

31. Sriramaneni RN, Omar AZ, Ibrahim SM, Amirin S, Mohd Zaini A. Vasorelaxant effect of diterpenoid lactones from Andrographis paniculata chloroform extract on rat aortic rings. Pharmacognosy Res. 2010;2(4):242-6. doi: 10.4103/09748490.69125.

32. Textor SC, Wilcox CS. Renal artery stenosis: Acommon, treatable cause of renal failure? Annu Rev Med. 2001;52:421-42. doi: 10.1146/annurev.med.52.1.421

33. Amiri F, García R. Renal angiotensin II receptor regulation in two-kidney, one clip hypertensive rats: effect of ACE inhibition. Hypertension. 1997;30(3):337-44.

34. Kobayashi S, Ishida A, Moriya H, Mori N, Fukuda T, Takamura T. Angiotensin II receptor blockade limits kidney infury in two-kidney, one-clip Goldblatt hypertensive rats with special reference to phenotypic changes. J Lab Clin Med. 1999;133(2):134-43

35. Sakamoto T, Chen C, Lokhandwala M. Contribution by bradykinin to the natriuretic response to the angiotensin converting enzyme inhibitor ramiprilat in spontaneously hypertensive rats. Naunyn-Schmiedebergs Arch Pharmacol. 1994;350(1):84-9.

36. Emura K, Yokomoto A, Toyoshi T, Moriwak M. Effect of enzymatically modified isoquercitrin in spontaneously hypertensive rats. J Nutr Sci Vitaminol. 2007;53(1):68-74. doi: 10.3177/jnsv.53.68

37. Motoyama K, Koyama H, Moriwaki M. Atheroprotective and plaque-stabilizing effects of enzymatically modified isoquercitrin in atherogenic apoE-deficient mice. Nutrition. 2009;25(4):421-7. doi: 10.1016/j.nut.2008.08.013

38. Panda S, Kar A. Antidiabetic and antioxidative effects of Annona squamosa leaves are possibly mediated through quercetin-3-O-glucoside. Biofactors. 2007;31(3):201-10. doi: 10.1002/biof.5520310307.

Article History: Submission Date: 10-09-16; Received Date: 15-09-16; Acceptance Date: 22-10-16.

Cite this article: Junior AG, Prando TBL, Gebara KS, Gasparotto FM, Lívero FAR, Lima DP, Gomes RS, Lourenço ELB. Protective Cardiorenal Effects Of Tropaeolum majus L. In Rats With Renovascular Hypertension. J Young Pharm. 2017;9(2):251-7. 